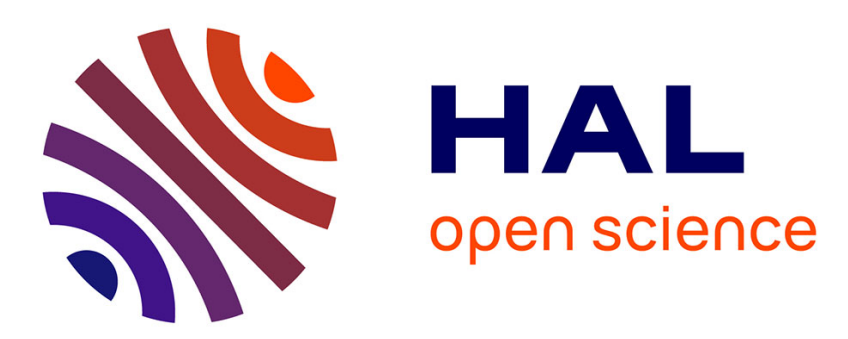

\title{
Choice overload, coordination and inequality: three hurdles to the effectiveness of the compensation mechanism?
}

\author{
Estelle Midler, Charles C. Figuieres, Marc Willinger
}

\section{- To cite this version:}

Estelle Midler, Charles C. Figuieres, Marc Willinger. Choice overload, coordination and inequality: three hurdles to the effectiveness of the compensation mechanism?. 2013. hal-02806611

\section{HAL Id: hal-02806611 https://hal.inrae.fr/hal-02806611}

Preprint submitted on 6 Jun 2020

HAL is a multi-disciplinary open access archive for the deposit and dissemination of scientific research documents, whether they are published or not. The documents may come from teaching and research institutions in France or abroad, or from public or private research centers.
L'archive ouverte pluridisciplinaire HAL, est destinée au dépôt et à la diffusion de documents scientifiques de niveau recherche, publiés ou non, émanant des établissements d'enseignement et de recherche français ou étrangers, des laboratoires publics ou privés. 


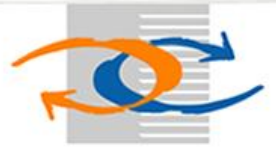

\title{
L A M E T A
}

Laboratoire Montpelliérain d'Economie Théorique et Appliquée

U M R

Unité Mixte de Recherche

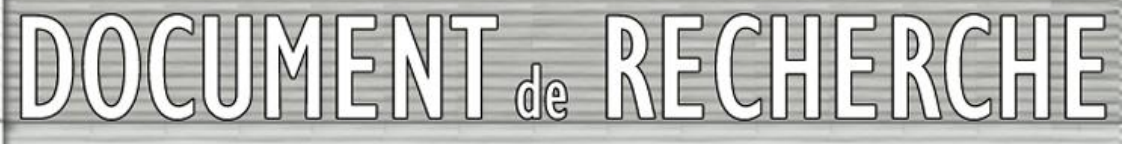

\author{
«Choice overload, coordination and \\ inequality: threehurdles to the \\ effectiveness of the \\ compensationmechanism?»
}

Estelle MIDLER Charles FIGUIÈRES Marc WILLINGER

$$
\text { DR n²013-01 }
$$

Unite de Formation et de Recherche d'Economie Avenue Raymond DUGRAND C.S. 79606 34960 MONTPELLIER Cedex 2

E-mail : lameta@lameta.univ-montp1.fr web : www.lameta.univ-montp1.fr 


\title{
Choice overload, coordination and inequality: three hurdles to the effectiveness of the compensation mechanism?
}

\author{
Estelle Midler*, Charles Figuières and Marc Willinger
}

February 11, 2013

\begin{abstract}
In this paper we test the effectiveness of a compensation mechanism when a negative externality is produced. It allows agents suffering from the negative externality to compensate those who reduce its production. Transfers are implemented via a two-stage design which is an adaptation of Varian's mechanism. It has been previously tested in the lab with different types of games, and its effectiveness turns out to depend on the experiment, for unclear reasons which we try to decipher in this paper. Three possible explanations, choice overload, mere coordination and inequality, are proposed and studied. We show that, other things equal, the larger the size of the strategy space, the lower the mechanism's efficiency (choice overload effect). Perhaps surprisingly, the data show that the appearance of additional equilibria does not jeopardize effectiveness (no mere coordination effect). Finally, inequality of outcomes plays a key role (fairness effect).
\end{abstract}

Keywords: compensation mechanism, experiment, externalities.

JEL Classification: C90, H23, H87.

*Basque Center for Climate Change (BC3), 48008, Bilbao, Spain. email: estelle.midler@bc3research.org 
The conflict between individual rationality and collective rationality is a momentous topic in normative economics. This conflict can take many forms. Typical examples are provided by major environmental problems regularly found in daily newspapers. By and large, various decisions around the world, such as $\mathrm{CO}_{2}$ emissions, are rational at individual levels; but they generate negative externalities that are not taken into account by agents and, therefore, are not rational at the collective level, i.e. they are not Pareto optimal decisions.

In this paper we confine ourselves to this important case of negative externalities. It encompasses two types of conflict. Firstly, there is the above mentioned conflict between individual rationality and collective rationality: finding a way to reconcile these two levels of rationality is the efficiency challenge in conflict resolution. Secondly, there is another conflict related to the first, because removing inefficiency also implies to arbitrate between individual interests. Indeed, Pareto optimal allocations are usually not unique and involve different distributions of well-beings. This is the fairness challenge in conflict resolution. From the "externality" point of view, conflict resolution is therefore a struggle against inefficiency and unfairness, under the form of some public intervention.

In the economic literature, some mechanisms have been proposed to solve externality problems, including the Compensation Mechanism (CM henceforth). The CM has been popularized by Varian (1994) and is based on seminal works by Guttman $(1978,1987)$ and Danziger and Schnytzer (1991). It is meant to solve externality problems when the regulator is not informed about agents' preferences.

Applied to negative externalities problems, it would take the form of a two-stage game in which the agents who produce the negative externality are called to compensate the agents who suffer from it. This compensation is determined in the first stage where each agent has to choose a price for the externality. In the second stage, agents choose between different levels of actions (for instance $\mathrm{CO}_{2}$ emissions) and their associated levels of externality. In theory, such a CM implements a Pareto optimal outcome as a Subgame perfect Nash equilibrium.

A few previous experiments have focused on the CM, and together they do not deliver a clear message, so far, about its ability to reconcile individual behaviors with social efficiency. Some ex- 
periments conclude that the CM is rather effective (Andreoni and Varian, 1999, Chen and Gazzale, 2004, Bracht, 2010). Another set of experiments, on the contrary, casts some doubt on the effectiveness of the compensation mechanism (Hamaguchi et alii, 2003, Bracht et alii, 2008, Charness et alii, 2007).

If we were to give an intuitive, though imprecise, explanation to these differences in the results, we would say that the mechanism seems to work correctly when subjects interact in relatively simple decision contexts. When inspecting things more closely, games where the CM "fails": 1) have strategy spaces richer than those in which it works ${ }^{1}, 2$ ) are characterized by a multiplicity of equi$\operatorname{libria}^{2}$, and 3) offer various distributions of equilibrium payments (associated with the multiplicity of equilibria). Therefore, if complexity undermines the good properties of the CM, it remains to inspect the role played, separately, by the length of calculations (richness of strategy spaces), 60 the difficulty of coordination faced by subjects (due to multiple equilibria and expectations about others' behavior) and individuals' concern for equity.

These are the general questions we address in this paper, using a simple game experiment with a unilateral negative externality. Could the number of options alone, faced by agents in the negotiation phase, have an impact on the ability of the CM to resolve the efficiency challenge of conflict? Could cooperation fall when only the number of equilibria increases, while the number of options and the distribution of payoffs remain unchanged? And finally, could mere inequality in payoffs distribution undermines the effectiveness of the CM (fairness challenge in conflict resolution)?

We show that, other things equal, the larger the size of the strategy space, the lower the mechanism's ability to cope with the challenges posed by conflict. Perhaps surprisingly, the data show that this does not result from the appearance of additional equilibria. But the number of options itself does play a role. This suggests that the limited rationality of agents appears to be an obstacle. Last but not least, data show that an important hurdle to the effectiveness of the CM is the fairness challenge. However, the logic by which inequality undermines the CM performance is subtle. The appearance of more unequal equilibria are not necessarily associated with lower performances, for they may reinforce the appeal of other equilibria. Yet, the role of inequality that we have found

\footnotetext{
${ }^{1}$ They have continuous strategy sets or a larger number of options to choose.

${ }^{2}$ There is a unique subgame perfect Nash equilibrium in Andreoni and Varian, 1999, in Chen and Gazzale, 2004, and in Bracht, 2010. On the contrary, Hamaguchi et al (2003), Charness et al. (2007), and Bracht et al. (2008) have multiple equilibria.
} 
here sustains a result of Charness et al. (2007), who stated that when an equal payoff outcome is reachable the mechanism better reduces the conflict between individual and collective rationality.

The article is organized as follows. Section 2 explains the experimental design. Section 3 indicates what predictions about subjects' behaviors can be given, based both on standard rationality

80 Section 5 concludes.

\section{Experimental design}

The experiment consists of 6 treatments, and we have run 2 sessions of each treatment. A total of 232 subjects took part to the experiments. Student subjects were recruited from a pool of 5,000

85 2007) and took place at the LEEM (Experimental Economics Laboratory of Montpellier).

Sessions lasted two hours at most, which included the time required for reading the instructions and answering questions, and the time needed to pay subjects at the end of the session. Subjects were paid based on a period randomly drawn from their session, in order to avoid wealth effects. either 2 Euros (for students on campus) or 6 Euros (for students coming from outside the campus).

The experiment distinguishes two types of players, type 1 and type 2 . Each type 1 player was randomly paired with a type 2 player for the entire duration of a session. Each session was broken into 16 periods and had two parts. In the first part, which was also the first period, only players 1 had to take a decision; those decisions produced a negative externality on players 2 . This first part was a dictator game, which is arguably the simplest game that can be used to represent a negative externality problem. In the second part, which extends over the following 15 periods, the CM was introduced and subjects had the possibility to choose the price at which a possible reduction of the externality was to be compensated. Therefore the CM modifies the agents' decision context, in particular for players 2 who are no longer passive agents. From this second part, one can assess empirically the ability of the mechanism to induce efficient choices.

What makes the difference between treatments is the size of strategy spaces (i.e. the number of possible prizes for the externality, to be chosen by each player), the number of theoretical subgame 
perfect Nash equilibria, and the distribution of monetary payoffs. only. In part 1, Player 1's payoff is called $\Pi_{1,0}$ and Player 2's payoff is $\Pi_{2,0}$. Payoffs are shown in Table 7 below.
Table 1: Payoffs in part 1

\begin{tabular}{|c|c|c|}
\cline { 2 - 3 } \multicolumn{1}{c|}{} & $\begin{array}{c}\text { Player 1 } \\
\Pi_{1,0}\end{array}$ & $\begin{array}{c}\text { Player 2 } \\
\Pi_{2,0}\end{array}$ \\
\hline A & 8 & 32 \\
\hline B & $\mathbf{1 4}$ & $\mathbf{6}$ \\
\hline
\end{tabular}

From now on, payoffs tables will report Pareto optimal payoffs in italics. Payoffs associated with optimal decisions at the individual levels (which will also be Nash equilibria in Parts 2) are a passive role.

We may expect that, without any intervention, Players 1 will not choose the socially optimal solution. However, some subjects may choose option A because they are willing to trade off their own material payoff to increase the social efficiency. Then, we want to check if the introduction

\footnotetext{
${ }^{3}$ The term externality is not used to describe the experiment to subjects. They only know about the two options, A and $\mathrm{B}$, and the corresponding payoffs.
} 


\subsection{Part 2: the mechanism}

In the second part of the experiment, we introduce the two-stage compensation mechanism to check its ability to solve the social dilemma. With the mechanism, Player 2 can decide to compensate Player 1 if he chooses option A rather than option B ${ }^{4}$. More precisely:

1. In the first stage, the announcement stage, Player 1 announces the magnitude of the price $t_{1} \geq 0$ for the externality. Simultaneously, Player 2 announces a level of price $t_{2} \geq 0$. And the regulator collects those prices.

2. In the second stage, Player 1 chooses how much externality he produces, i.e. A or B. At the end of the second stage, transfers are enforced by the regulator as follows. Player 1 receives:

$$
T_{1}=\left\{\begin{array}{cl}
4 * t_{2}-\varepsilon\left|t_{1}-t_{2}\right| & \text { if Player } 1 \text { chooses option A } \\
0 & \text { otherwise }
\end{array}\right.
$$

In this expression, 4 is a scale parameter for the subsidy offered to Player 1, and $\varepsilon\left|t_{1}-t_{2}\right|, \epsilon>$ 0 is a penalty imposed to Player 1 in case announcements are not identical. For the parameterization of the mechanism in the lab, we chose $\epsilon=1$. The larger the difference between the unit prices of transfer chosen by both players, the higher the penalty ${ }^{5}$. Player 2 will be charged the following transfer:

$$
T_{2}=\left\{\begin{array}{cl}
4 * t_{1} & \text { if Player } 1 \text { chooses option A } \\
0 & \text { otherwise }
\end{array}\right.
$$

So, under the mechanism payoffs are as given in Table 2.

\footnotetext{
${ }^{4}$ The mechanism tested here is different from Varian's one, where Player 1 can compensate Player 2 for the negative externality he produces. His version is therefore not individually rational, Player 1 having no incentive to participate.

${ }^{5}$ Note that if Player 2 chooses $t_{2}>t_{1}$, transfers are not implemented. This is because what Player 1 receives, $4 * t_{2}$, cannot be larger than what Player 2 gives, $4 * t_{1}$. In theory, players choose $t_{1}=t_{2}$ and the problem does not arise. But in practice one may expect that some groups of subjects may choose different prices, so this subtlety has to be taken into account.
} 
Table 2: Payoffs in part 2

\begin{tabular}{|c|c|c|}
\hline & $\begin{array}{c}\text { Player } 1 \\
\Pi_{1}\end{array}$ & $\begin{array}{c}\text { Player } 2 \\
\prod_{2}\end{array}$ \\
\hline if Player 1 chooses $\mathrm{A}$ & $8+4 t_{2}-\left|t_{1}-t_{2}\right|$ & $32-4 t_{1}$ \\
\hline if Player 1 chooses B & 14 & 6 \\
\hline
\end{tabular}

The theoretical properties of the mechanism are analyzed under the assumption that agents play a game of complete information. Optimal individual choices are decided by backward induction ${ }^{6}$. In the continuous case, the mechanism implements a Pareto optimal outcome as a subgame perfect interior Nash equilibrium ${ }^{7}$. In the experiment we restrict ourselves to a discrete and finite version of the model. Thus players cannot choose any $t_{1}$ or $t_{2}$ within a continuum of values; rather they have the choice between different countable and finite levels of $t$, the number of which depends on the treatment. In real situations, individuals seldom choose within continuous sets of options. Continuous sets are often better viewed as approximations for real world situations characterized by abundance of options. However, a discrete number of options simplifies the understanding of the mechanism by subjects and is convenient to control for complexity of choices in our analysis; in the continuous case, there is invariably an infinity (actually a continuum) of equilibria.

Whether discrete or continuous, the theoretical effect of the mechanism is to transform an original game with a social dilemma into a coordination game. However, this coordination problem is quite complex. Actually, subjects face a triple coordination problem: $i$ ) they have to coordinate on an equilibrium, $i i$ ) they have to reach a Pareto optimal one (some Nash equilibria are not Pareto optimal), $i i i)$ they have to choose between different Pareto optimal equilibria with, presumably, different distributional properties. The larger the number of options proposed to subjects, the greater the risk of having a larger number of equilibria, compounding the problem of coordination and the fairness challenge as well.

In all treatments subjects knew the payoffs associated with each profile of decisions but they were not informed about the way such payoffs were calculated. Everything that was explained previously on the mechanism was not explained to subjects (see an example of instructions in

\footnotetext{
${ }^{6}$ We are therefore interested in Subgame Perfect Nash Equilibria, but for the sake of completeness it should be mentioned that there are also many other, not subgame perfect, equilibria in this simple game.

${ }^{7}$ The mechanism also has some fairness properties. For instance when applied to a public good framework, it induces a Lindhal equilibrium.
} 
Appendix 1 to check what subjects were really informed of). a moderate level of inequality (m). As for treatment $T_{5}^{6, l m}$, it has a perfectly egalitarian Pareto optimal equilibrium (1).

We will systematically investigate whether introducing the mechanism has an effect. To do so we will analyze the difference between Part 1 (without the mechanism) and Part 2 (with the mechanism) in every treatment.

In addition, treatments have been designed in order to test how the effectiveness of the CM is affected by: $i$ ) the number of options, $i i$ ) the number of equilibria, $i i i$ ) the inequality of equilibrium outcomes. In order to disentangle those effects we need to compare treatments with different sizes for strategy spaces, with different numbers of subgame perfect equilibria and with different distributions of payoffs.

A treatment will be denoted generically $T_{i}^{j, k}$, where subscript $i=2,3,5$ stands for its number of price options, superscript $j=2,3,6$ refers to its number of subgame perfect equilibria and superscript $k=h m, m, l m$ gives an indication about the distribution of Pareto equilibrium payoffs. Actually, Pareto optimal equilibrium payoffs can be: $(16,24),(24,16),(20,20)$ and $(28,12)$, where the first (resp. second) number in a vector gives Player 1's payoff (resp. Player 2's payoff). If inequality is measured by the payoffs gap, then superscript $m$ (for "moderate") indicates a treatment in which the payoffs gaps in Pareto equilibria can be only 8 (payoffs are $(16,24)$ and/or $(24,16)$ ). Superscript $h m$ indicates a treatment that features two payoffs gaps, high (equal to 16 in $(28,12)$ ) and moderate. Finally, superscript $l m$ indicates a treatment where two kinds of payoffs gaps occur, low (equal to 0 in $(20,20))$ and moderate.

We have run six treatments: $T_{2}^{2, m}, T_{3}^{2, m}, T_{3}^{3, m}, T_{5}^{3, m}, T_{5}^{6, h m}$ and $T_{5}^{6, l m}$. In all treatments, among the several prices of the externality that subjects can choose, there is the possibility to fall back to the laisser-faire, when $t_{i}=0$. Put differently, subjects always have the choice to participate or not in the compensation mechanism. Four treatments out of six, $T_{2}^{2, m}, T_{3}^{3, m}, T_{5}^{6, h m}$ and $T_{5}^{6, l m}$, are constructed with the mechanism and with a different number of options or equilibria. The two remaining treatments, $T_{3}^{2, m}$ and $T_{5}^{3, m}$, are constructed artificially as control treatments. It is also worth noting that, in all treatments except $T_{5}^{6, l m}$, the more equal Pareto optimal equilibrium has

\subsection{Treatments}


Table 3 below summarizes the different treatments and tests performed from their comparisons. From reading the first line, for example, the reader understands that only two treatments have

195 of equilibria nor the number of options have changed, but this test is useful to capture a possible role for inequality, since its level switches from high $(h)$ to low $(l)$. Finally, comparisons 1 and 2 mix up some or all of those effects.

Table 3: Comparisons of the different treatments

\begin{tabular}{|c|c|c|c|}
\hline $\begin{array}{l}\text { Number of } \\
\text { options } \\
\text { Number of } \\
\text { equilibria }\end{array}$ & 2 options & 3 options & 5 options \\
\hline 2 equilibria & $T_{2}^{2, m}$ & $T_{3}^{2, m}$ & \\
\hline 3 equilibria & & $T_{3}^{3, m}$ & $T_{5}^{3, m}$ \\
\hline 6 equilibria & & & $\begin{array}{c}T_{5}^{6, h m} \\
T_{5}^{6, l m}\end{array}$ \\
\hline
\end{tabular}

There is a correspondence between the price options in the different treatments and the underlying numerical values for prices given to the externality. This information was not delivered to subjects who simply had to choose among options presented as categorical variables, but we give it to the reader who wants to uncover how payoffs were calculated. The different possibilities are: 
- In Treatment $T_{2}^{2, m}$ each subject faces a binary choice for the price, where $t_{i}=0$ or $t_{i}=4$.

- In Treatment $T_{3}^{3, m}$ each subject has the choice between three options, $t_{i}=0, t_{i}=2$ or $t_{i}=4$.

\section{Predictions}

\subsection{Standard predictions}

Standard predicted behaviors are given by subgame perfect Nash equilibria. Of course, those predictions vary according to treatments. As an illustration, Appendix 1 provides full details in order to identify a subgame perfect Nash equilibrium for Treatment $T_{3}^{3, m}$. Appendix 2 shows the payoffs tables of each treatment (subgame perfect Nash equilibria are identified by bold characters). In each treatment, there are at least two subgame perfect Nash equilibria. One of them is the laisser-faire 
with zero compensation transfers. Among the other equilibria, at least one of them is also a Pareto optimal outcome. A summary of each treatment characteristics is given in Table 4 below.

Table 4: Treatments characteristics

\begin{tabular}{cccccccc}
\hline \hline Treatment & $\begin{array}{c}\text { Constructed } \\
\text { with the } \\
\text { mechanism }\end{array}$ & $\begin{array}{c}\text { Number of } \\
\text { participants }\end{array}$ & $\begin{array}{c}\text { Number } \\
\text { of options }\end{array}$ & $\begin{array}{c}\text { Number } \\
\text { of Nash } \\
\text { equilibria }\end{array}$ & $\begin{array}{c}\text { Number } \\
\text { of optimal } \\
\text { outcomes }\end{array}$ & $\begin{array}{c}\text { Number } \\
\text { of optimal } \\
\text { equilibria }\end{array}$ & $\begin{array}{c}\text { Level of } \\
\text { inequality of } \\
\text { opt. equilibria }\end{array}$ \\
\hline$T_{2}^{2, m}$ & yes & 36 & 2 & 2 & 3 & 1 & $\mathrm{~m}$ \\
$T_{3}^{3, m}$ & yes & 40 & 3 & 3 & 6 & 2 & $\mathrm{~m}, \mathrm{~m}$ \\
$T_{3}^{2, m}$ & no & 40 & 3 & 2 & 5 & 1 & $\mathrm{~m}$ \\
$T_{5}^{6, h m}$ & yes & 38 & 5 & 6 & 15 & 3 & $\mathrm{~m}, \mathrm{~m}, \mathrm{~h}$ \\
$T_{5}^{3, m}$ & no & 38 & 5 & 3 & 15 & 2 & $\mathrm{~m}, \mathrm{~m}$ \\
$T_{5}^{6, l m}$ & yes & 40 & 5 & 6 & 15 & 3 & $\mathrm{~m}, \mathrm{~m}, 1$ \\
\hline
\end{tabular}

Cooper et al. (2003) provided experimental evidence about systematic differences between players' choices in the strategic and extensive form representations, although the underlying games are strategically equivalent. One must be aware that each possibility - extensive of strategic form - then features a framing bias. Sequentiality is often presented using the extensive form of the game. We have both sequentiality - because the game involves two stages - and simultaneity, in the first stage. To simplify as much as possible the subjects' task and to ease their understanding we decided to rely on a combination of those two frameworks. Stage 1 of the game was framed as a simultaneous move game for which the outcome was a decision tree for Player 2 (see appendix 1 for an illustration).

\subsection{Behavioral conjectures}

The experimental literature on the CM is limited but, combined with other experimental evidence, it casts doubts on the reliability of the predictions based on standard assumptions regarding rationality. Three conjectures can be made about the effectiveness of the CM in face of complexity.

Firstly, the effectiveness of the CM might be compromised if the number of choice options is increased without affecting the equilibria. In other words, adding "irrelevant alternatives" or "dominated alternatives" might nevertheless influence subjects' choices. There are two main reasons for that: "choice overload" and "changing the reference point". The choice overload effect has been 
documented by the social psychology literature (see for instance Iyengar and Kamenica, 2010) ${ }^{8}$. It arises under the presumption that subjects are boundedly rational, i.e. in decision-making, individuals' rationality is limited by the information they have, the finite amount of time they have to make a decision and their cognitive limitations (Simon, 1955, Kahneman, 2003). Increasing the number of options increases the cognitive load for subjects because of a higher computational complexity. Therefore if subjects are boundedly rational, they might be less successful in matching theoretical predictions. Hence the conjecture:

Conjecture 1. Other things equal, increasing the number of strategies has a negative impact on the effectiveness of the CM.

Secondly, increasing the number of choice options may simultaneously increase the number of Nash-equilibria, creating thereby a sharper coordination issue. Even if the number of options and the level of inequality remains constant, increasing the number of equilibria can possibly undermines the good properties of the CM. Let us call this a mere coordination effect (for a general presentation of coordination issues, see Cooper, 1998).

Conjecture 2. Other things equal, increasing the number of equilibria has a negative impact on the effectiveness of the CM.

Finally, if the CM allows for multiple Nash equilibria, the equilibrium payoff distribution may matter. Keeping the number of options and the number of Nash equilibria unchanged, we therefore expect that the CM is more effective in games where it allows for less unequal equilibrium payoff distributions (see for instance Charness et alii, 2007). This would be a fairness effect. Accordingly, let us make the following conjecture:

Conjecture 3. Other things equal, the effectiveness of the CM is sensitive to the distribution of payoffs in the set of Pareto optimal equilibria.

\section{${ }_{275} 4$ Experimental results}

First we checked if "type 1"-players choose significantly more the laissez-faire option B in the first part of the experiment to confirm the initial presence of a social dilemma.

\footnotetext{
${ }^{8}$ Iyengar and Kamenica (2010) showed in particular that a choice overload effect can arise when people face too many possibilities and that this effect could have a negative impact on the capacity of players to devise a strategy
} 
In total, 29 of the 116 "type 1"-subjects choose option A in the first part (25\%). We have run an exact binomial test and found that "type 1"-subjects choose options B significantly more often than option A (p-value=0.000). However, this result means that $25 \%$ of subjects apparently do not choose to maximize their own payoff in the first part. This might be due to the high difference of social welfare between option A and option B. Presumably, a minority of "type 1"-subjects seems willing to make a personal (small) sacrifice in order to substantially increase the social outcome.

Also, we found no significant difference, at a 5\% level, between all treatments in Part 1 when we compare them with one another. Finally, we also tested the possibility that subjects were able to play at random in the second part. The data reject this possibility.

\subsection{Is the mechanism effective?}

Our first goal is to check whether the mechanism is effective, that is to say, roughly speaking, whether it navigates subjects towards a Pareto Optimal outcome.

Figure 1 shows the evolution, for each treatment, of the frequency of groups that reach an optimal outcome, before and after the mechanism is introduced. As we can see, for all treatments, the observed frequency of optimal outcomes is increasing between periods 1 and 2 and also slightly increasing between periods 2 and 16. Notice that, although the effect of the mechanism is spectacular in Treatment $T_{2}^{2, m}$, it is clearly not of the same force in the other treatments.

Table 5 below reports global results about the frequency of groups reaching a Pareto optimum (PO). As we can see from the second column, this frequency increases between part 1 and part 2 in all treatments. It is worth noting that this frequency is at its lowest level under the treatment that contains the most unequal equilibrium (in Treatment $T_{5}^{6, h m}$ ). For the purpose of analysis, the last column indicates the share of groups achieving a PO as a Nash equilibrium (PONE). It is interesting to distinguish PO from PONE, since in principle only those of the second category allows us to assess the performance of the mechanism. This frequency is the lowest in Treatment $T_{5}^{3, m}$, which is also one of the least effective treatment. In this treatment, inequality and the number of equilibria are moderate, while the number of options is the largest.

Table 6 provides data about social welfare and payoffs. Results from Part 2 are averages over 15 periods. We can see that the social welfare is higher with the mechanism than without the mechanism, whatever the treatment. However these increases are clearly more important in some 
Figure 1: Frequency of groups reaching an optimal outcome

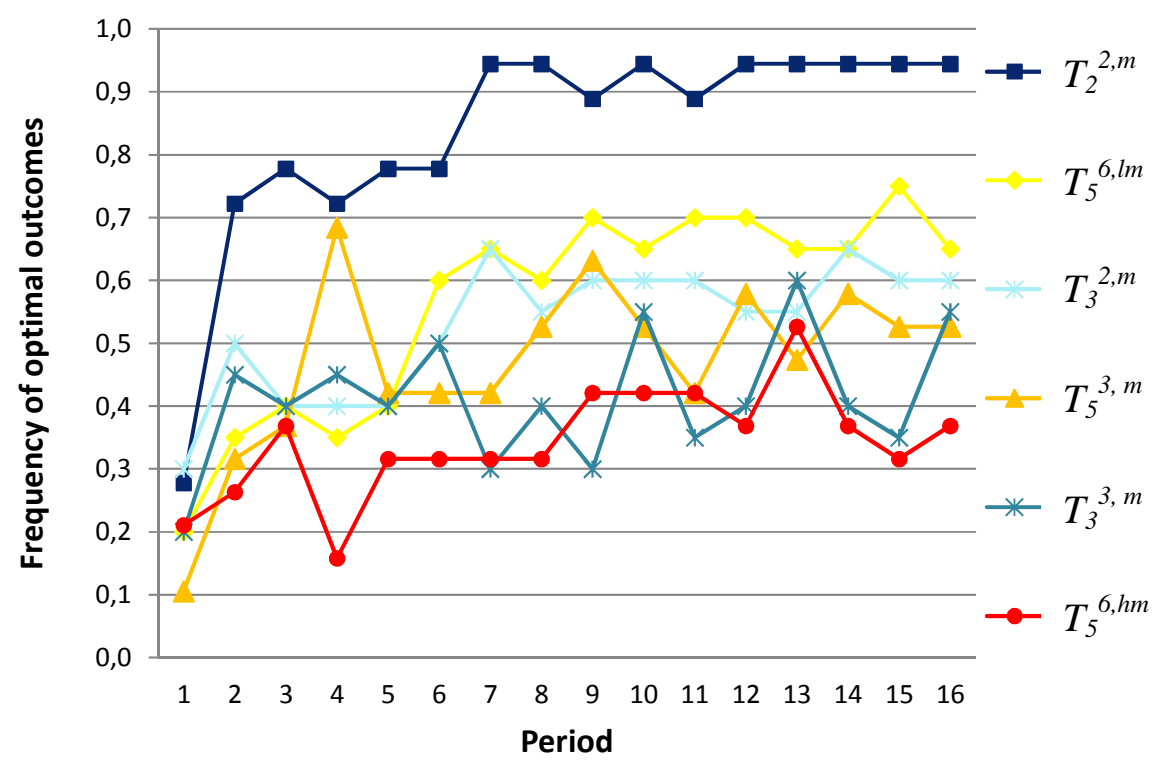

treatments, particularly in treatments $T_{2}^{2, m}$ and $T_{5}^{6, l m}$. Also, in both part, Player 1's payoff is always higher than Player 2's payoff.

In order to test the effectiveness of the mechanism we compare, for each treatment, the choices of groups in Part 1 (without the mechanism) and Part 2 (with the mechanism). In theory, the mechanism is effective in the sense that subjects should switch to a PO in all periods. Such a criterion would be too harsh; in practice one must anticipate a few subtleties and define a more pragmatic rule to judge effectiveness.

Firstly, there can be a movement towards optimality, but that is not systematic in all periods, with occasional failures in some periods that are relatively marginal. For part 2, which is made of 15 periods, we declare that a group has reached a PO if such a profile is achieved at least 8 times (that is to say, more than once in two $)^{9}$.

Secondly, a gain in efficiency, if any, clearly comes from groups that have chosen a different option. But some groups may have switched from non optimality to optimality whereas other groups may have done the opposite. So we will measure a gain by counting groups who did not

\footnotetext{
${ }^{9}$ Alternatively, one may perform the comparison between Part 1 and any period in Part 2. It turns out that this alternative criterion does not change the results of this section. Details are available upon request from the authors
} 
Table 5: Effectiveness of the CM across treatments

\begin{tabular}{cccc}
\hline \hline Treatment & \multicolumn{2}{c}{ Frequency of } \\
& \multicolumn{2}{c}{ groups reaching } & Frequency of \\
& PO $(\%)$ & PONE among \\
PO in Part 2 \\
$T_{2}^{2, m}$ & 27.8 & Part 2 & $(\%)$ \\
$T_{3}^{3, m}$ & 20.0 & 42.7 & 99.5 \\
$T_{3}^{2, m}$ & 30.0 & 54.3 & 92.0 \\
$T_{5}^{6, h m}$ & 21.1 & 35.1 & 97.6 \\
$T_{5}^{3, m}$ & 10.5 & 49.5 & 78.0 \\
$T_{5}^{6, l m}$ & 20.0 & 58.7 & 98.8 \\
\hline
\end{tabular}

Table 6: Data about payoffs

\begin{tabular}{ccccccc}
\hline \hline \multirow{2}{*}{ Treatment } & \multicolumn{2}{c}{ Social } & \multicolumn{2}{c}{ Player 1's } & \multicolumn{2}{c}{ Player 2's } \\
& \multicolumn{2}{c}{ Welfare } & \multicolumn{2}{c}{ payoff } & \multicolumn{2}{c}{ payoff } \\
& Part 1 & Part 2 & Part 1 & Part 2 & Part 1 & Part 2 \\
\hline$T_{2}^{2, m}$ & 25.56 & 37.30 & 12.33 & 22.50 & 13.22 & 14.80 \\
$T_{3}^{3, m}$ & 24.00 & 31.04 & 12.81 & 16.11 & 11.20 & 14.93 \\
$T_{3}^{2, m}$ & 26.00 & 32.07 & 12.20 & 18.77 & 13.80 & 13.30 \\
$T_{5}^{6, h m}$ & 24.21 & 29.78 & 12.74 & 17.07 & 11.47 & 12.71 \\
$T_{5}^{3, m}$ & 22.11 & 32.17 & 13.37 & 18.38 & 8.74 & 13.79 \\
$T_{5}^{6, l m}$ & 24.00 & 33.86 & 12.80 & 18.90 & 11.20 & 17.10 \\
\hline
\end{tabular}


reach an optimal equilibrium in Part 1, then reached one in Part 2, diminished by the subjects who reached the opposite outcomes, namely an optimal equilibrium in part 1 followed by a non optimal one in part 2.

Given those pragmatic provisos, we adopt the following definition of effectiveness. to an optimal one and the number of groups moving in the opposite direction for each treatment. The number of groups switching from an non optimal to optimal outcome is significantly larger in treatments $T_{2}^{2, m}$ and $T_{5}^{6, l m}$ only (MacNemar, two-sided, p-values reported in table 7).

Table 7: Effectiveness of the mechanism in all treatments

\begin{tabular}{cccc}
\hline \hline Treatment & $\begin{array}{c}\text { Number of groups } \\
\text { switching to } \\
\text { option B } \\
\text { in Part 2 }\end{array}$ & $\begin{array}{c}\text { Number of groups } \\
\text { switching to } \\
\text { option A } \\
\text { in Part 2 }\end{array}$ & $\begin{array}{c}\text { Binomial Test } \\
\text { p-value }\end{array}$ \\
\hline$T_{2}^{2, m}$ & 0 & 12 & 0.0005 \\
$T_{3}^{3, m}$ & 2 & 3 & 1 \\
$T_{3}^{2, m}$ & 3 & 7 & 1 \\
$T_{5}^{6, h m}$ & 3 & 5 & 1 \\
$T_{5}^{3, m}$ & 2 & 7 & 0.4531 \\
$T_{5}^{6, l m}$ & 1 & 10 & 0.0215 \\
\hline
\end{tabular}

It seems that when the number of possible options for subjects in the first stage gets larger, or when the number of equilibria increases, the effectiveness of the mechanism is reduced, except, possibly, if the increase of these two dimensions is associated with the appearance of an equalpayoffs PONE. This result appears clearly on figure 1: we can see that the frequency of optimal outcomes is higher in Treatment $T_{2}^{2, m}$. Then comes $T_{5}^{6, l m}$ and the remaining treatments are less distinguishable. 
We then wonder if these differences between treatments are significant. We restrict the analysis to treatments $T_{2}^{2, m}, T_{3}^{3, m}$ and $T_{5}^{6, h m}$, which have in common to be based entirely on the mechanism, without artificial outcomes (the last treatment that shares this characteristic, $T_{5}^{6, l m}$, will be devoted a special attention later in Section 3.3). Since there is no significant differences between treatments in Part 1, we can compare the number of times groups reach an optimal equilibria in the second part between treatments $T_{2}^{2, m}, T_{3}^{3, m}$ and $T_{5}^{6, h m}$. If we observe a difference in part 2, it should therefore come from the mechanism itself.

Table 8 shows the data. The first column indicates the treatment. The second column indicates how many times groups reached a PONE in average in this treatment between period 2 and period 6. The last column indicates how many times in all periods groups reached an optimal equilibrium in average in this treatment. For example, in Treatment $T_{2}^{2}$, over 15 periods (from periods 2 and 16), groups reached 13.06 times an optimal equilibrium in average.

Table 8: Number of times groups reach an optimal equilibrium in average in each treatment

\begin{tabular}{ccccc}
\hline \hline Treatment & Periods 2-6 & Periods 7-11 & Periods 12-16 & Total \\
\hline$T_{2}^{2, m}$ & 3.78 & 4.61 & 4.67 & 13.06 \\
$T_{3}^{3, m}$ & 2.00 & 1.70 & 2.20 & 5.90 \\
$T_{5}^{6, h m}$ & 1.32 & 1.89 & 1.95 & 5.16 \\
\hline
\end{tabular}

Here we only want to check whether the observed difference of effectiveness between treatments is significant.

Result 2. Consistently with Conjectures 1, 2 and 3, the number of times a group reaches an optimal equilibrium is always significantly higher in Treatment $T_{2}^{2, m}$ than in Treatments $T_{3}^{3, m}$ or $T_{5}^{6, h m}$.

Support for result 2. Table 9 reports the results of Mann-Whitney (two-sided) tests. The first cell shows the p-value (0.0028) for the comparison between $T_{2}^{2, m}$ and $T_{3}^{3, m}$ for period 2 to 6 . From Table 9, the number of times a group reaches a socially optimal equilibrium is significantly higher in $T_{2}^{2, m}$ than in $T_{3}^{3, m}$. This is true not only if we look at all the periods, but also when we look at the first five periods, the five intermediate periods and the five last periods. Finally, there is always a significant difference between $T_{2}^{2, m}$ and $T_{5}^{6, h m}$.

However: 
Table 9: Comparison of the number of times groups reach an optimal outcome between treatments (Mann-Whitney)

\begin{tabular}{|c|c|c|c|c|}
\hline Comparisons & $\begin{array}{c}\text { Periods } \\
2 \text { to } 6 \\
\text { p-value }\end{array}$ & $\begin{array}{l}\text { Periods } \\
7 \text { to } 11 \\
\text { p-value }\end{array}$ & $\begin{array}{l}\text { Periods } \\
12 \text { to } 16 \\
\text { p-value }\end{array}$ & $\begin{array}{c}\text { All } \\
\text { periods } \\
\text { p-value }\end{array}$ \\
\hline$T_{2}^{2, m}-T_{3}^{3, m}$ & $\begin{array}{c}0.0028 \\
* * *\end{array}$ & $\begin{array}{c}0.0000 \\
* * *\end{array}$ & $\begin{array}{c}0.0001 \\
* * *\end{array}$ & $\begin{array}{c}0.0000 \\
* * *\end{array}$ \\
\hline$T_{2}^{2, m}-T_{5}^{6, h m}$ & $\begin{array}{c}0.0003 \\
* * *\end{array}$ & $\begin{array}{c}0.0001 \\
* * *\end{array}$ & $\begin{array}{c}0.0002 \\
* * *\end{array}$ & $\begin{array}{c}0.0000 \\
* * *\end{array}$ \\
\hline$T_{3}^{3, m}-T_{5}^{6, h m}$ & $\begin{array}{c}0.1457 \\
-\end{array}$ & $\begin{array}{c}0.9654 \\
-\end{array}$ & $\begin{array}{c}0.3865 \\
-\end{array}$ & $\begin{array}{c}0.2833 \\
-\end{array}$ \\
\hline
\end{tabular}

Result 3. The number of times a group reaches an optimal equilibrium is never significantly higher in Treatment $T_{3}^{3, m}$ than in $T_{5}^{6, h m}$.

Support for result 3. Using Table 9 again, if we compare $T_{3}^{3, m}$ and $T_{5}^{6, h m}$, we find that there is no difference between those two treatments.

To summarize, the mechanism is always efficient in $T_{2}^{2, m}$, but this is rarely the case in $T_{3}^{3, m}$ and $T_{5}^{6, h m}$. The mechanism is also significantly more efficient in $T_{2}^{2, m}$ than in $T_{3}^{3, m}$ and $T_{5}^{6, h m}$. The difference between $T_{3}^{3, m}$ and $T_{5}^{6, h m}$ is not significant. It seems that the negative impact of the number of options, the number of equilibria, and to a less extent inequality, loses its strength rapidly as one moves away from the simple game with two options. Put another way, there seems to be a qualitative break in behaviors between the game with two options and the other games, as if another type of rationality was at work when strategy spaces include at least three possibilities. It may be that in simple games, the rationality of the subjects is the usual type, but in richer environments subjects take their decisions using heuristics, which are not affected by the number of options and the number of equilibria. But this heuristic might depend on inequality (more on this in Section 4.3). That would make sense, when these heuristics are meant to be a general solution found by the subjects to cope with the part of complexity linked to the size of the strategy spaces and/or the multiplicity of equilibria.

As mentioned earlier, complexity might play a role via at least three different channels: $i$ ) 
agents' bounded rationality, that is their limited ability or proclivity to perform longer computations, $i i)$ the coordination problem that may arise when larger strategy spaces also means larger number of equilibria, iii) agents' concern for fair outcomes. The next section investigates the potential of those explanations.

\subsection{Number of options versus number of equilibria}

As we have seen in section 4.1, there is a significant difference between Treatments $T_{2}^{2, m}$ and $T_{3}^{3, m}$. We will therefore analyze this difference, using ad hoc Treatment $T_{3}^{2, m}$ in order to disentangle the effect of the number of options from the effect of the number of equilibria. Recall that in $T_{2}^{2, m}$, the game has two options, two NE and only one of which is a PONE. In $T_{3}^{2, m}$, the game has three 390 options, two NE and only one of which is a PONE as in $T_{2}^{2, m}$. In Treatment $T_{3}^{3, m}$, the game has three options, but also three NE, two of which being a PONE.

Figure 1 in the previous section shows the frequency of groups reaching an optimal outcome. This frequency seems higher in $T_{2}^{2, m}$ than in $T_{3}^{2, m}$, and higher in $T_{3}^{2, m}$ than in $T_{3}^{3, m}$. Let us look again at the number of times a group reaches an optimal equilibrium in each of these three treatments (Table 10). If a choice overload effect (Conjecture 1) and a mere coordination effect (Conjecture 2) are at work, we should find a significant difference between $T_{2}^{2, m}$ and $T_{3}^{2, m}$, and between $T_{3}^{2, m}$ and $T_{3}^{3, m}$ respectively.

Table 10: Average number of times groups reach an optimal equilibrium in each treatment

\begin{tabular}{ccccc}
\hline \hline Treatments & Periods 2-6 & Periods 7-11 & Periods 12-16 & Total \\
\hline$T_{2}^{2, m}$ & 3.78 & 4.61 & 4.67 & 13.06 \\
$T_{3}^{3, m}$ & 2.00 & 1.70 & 2.20 & 5.90 \\
$T_{3}^{2, m}$ & 2.10 & 2.95 & 2.90 & 7.95 \\
\hline
\end{tabular}

Clearly, the difference in frequencies across those treatments comes partly from the change in the number of options and partly from the number of equilibria (since inequality in the distribution of payoffs is the same in those treatments).

A possibility to quantify the contribution of each explanation is to calculate the share of the variation that comes from each of these two changes. This is done in Table 11, which shows that 
$71.4 \%$ of the difference of effectiveness could be attributed to the change in the number of options $\left(T_{2}^{2, m}-T_{3}^{2, m}\right)$, whereas only $28.6 \%$ would be associated to the change in the number of equilibria ${ }_{405}\left(T_{3}^{2, m}-T_{3}^{3, m}\right)$.

Table 11: Variations in the number of times groups reach an optimal equilibrium between treatments

\begin{tabular}{ccc}
\hline \hline Treatments & Absolute variations & Shares (\%) \\
\hline$T_{2}^{2, m}-T_{3}^{3, m}$ & 7.16 & 100.00 \\
$T_{2}^{2, m}-T_{3}^{2, m}$ & 5.11 & 71.40 \\
$T_{3}^{2, m}-T_{3}^{3, m}$ & 2.05 & 28.60 \\
\hline
\end{tabular}

Mann-Whitney tests for the comparisons between $T_{2}^{2, m}, T_{3}^{3, m}$ and $T_{3}^{2, m}$ regarding the number of time a group reaches an optimal equilibrium are shown in Table 12.

Table 12: Comparisons of the number of times groups reach an optimal outcome between treatments (Mann-Whitney)

\begin{tabular}{ccccc}
\hline \hline & Periods & Periods & Periods & All \\
Comparisons & 2 to 6 & 7 to 11 & 12 to 16 & periods \\
& p-value & p-value & p-value & p-value \\
\hline$T_{2}^{2, m}-T_{3}^{3, m}$ & 0.0028 & 0.0000 & 0.0001 & 0.0000 \\
& $* * *$ & $* * *$ & $* * *$ & $* * *$ \\
$T_{2}^{2, m}-T_{3}^{2, m}$ & 0.0054 & 0.0012 & 0.0047 & 0.0012 \\
& $* * *$ & $* * *$ & $* * *$ & $* * *$ \\
$T_{3}^{3, m}-T_{3}^{2, m}$ & 0.9233 & 0.0246 & 0.3811 & 0.2713 \\
& - & $* *$ & - & - \\
\hline
\end{tabular}

Result 4. Consistently with Conjecture 1 (choice overload effect), increasing the number of options, from 2 to 3, without increasing the number of equilibria and without changing the inequality in the distribution of PONE payoffs has a negative impact on the effectiveness of the CM.

Support for result 4. The second line of Table 12 shows that the number of times a group reaches an optimal equilibrium is significantly higher in $T_{2}^{2, m}$ than in $T_{3}^{2, m}$. We conclude that, when the number of options increases from 2 to 3, all things being equal, groups fail to coordinate on a PONE more often. 
Result 5. In contradiction with Conjecture 2 (coordination effect), increasing the number of equilibria, from 2 to 3, without increasing the number of options or without changing the inequality in the distribution of PONE payoffs, has no significant impact on the effectiveness of the CM.

Support for result 5. The third line of table 12 shows that there is no significant difference between $T_{3}^{3, m}$ and $T_{3}^{2, m}$ for all periods, with the exception of periods 7-11. We conclude that, when the number of equilibria increases from 2 to 3 and the number of options and the inequality remain unchanged, it does not become harder for groups to coordinate on a optimal equilibria.

\subsection{Impact of inequality on the effectiveness of the mechanism}

Treatments that are best suitable to appraise the role of inequality are $T_{5}^{6, l m}$ and $T_{5}^{6, h m}$. Both treatments are constructed with the mechanism, and have the same number of options and of equilibria. But Treatment $T_{5}^{6, l m}$ has a PONE with equal payoffs, whereas in Treatment $T_{5}^{6, h m}$ all PONE feature some degree of inequality. Figure 2 shows the frequency of groups achieving a PO in those two treatments.

Figure 2: Frequency of groups reaching a PO in Treatments $T_{5}^{6, h m}$ and $T_{5}^{6, l m}$

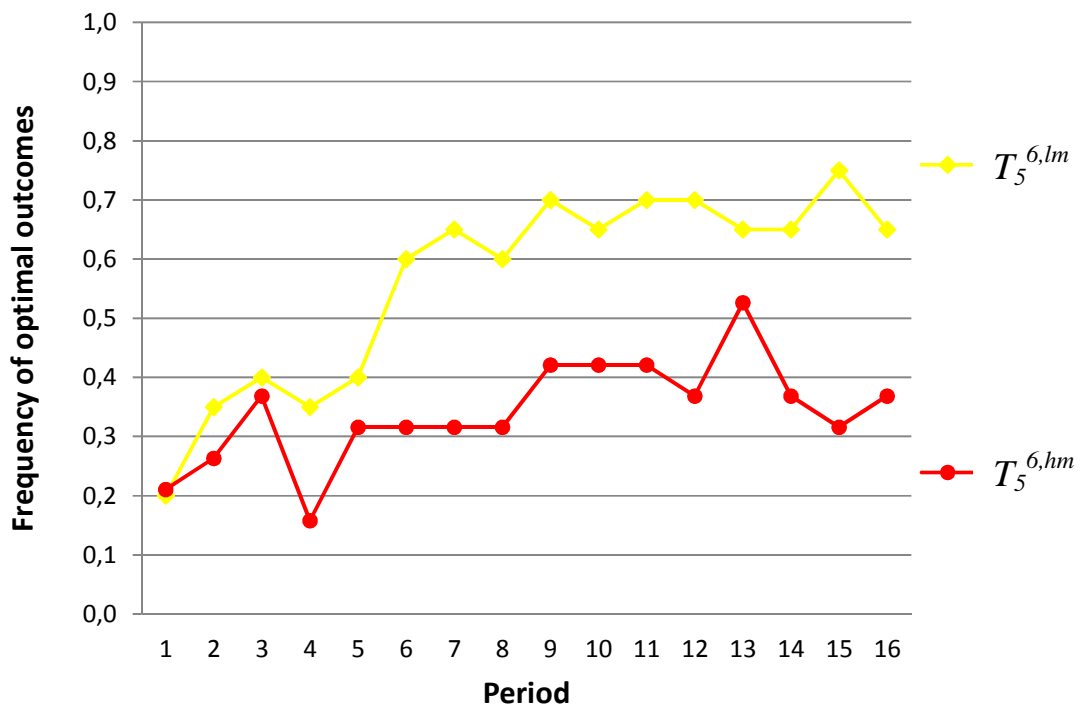

A first possibility in order to check Conjecture 3 (fairness effect) is to question the effectiveness of the CM in those two treatments. We already know, from results of Section 4.1, that the CM is 
430 It shows data about the average number of times groups reach a PONE in those two treatments, in total and in several sub-periods of Part 2.

Table 13: Average number of times groups reach an optimal equilibrium in $T_{5}^{6, h m}$ and $T_{5}^{6, l m}$

\begin{tabular}{ccccc}
\hline \hline Treatments & Periods 2-6 & Periods 7-11 & Periods 12-16 & Total \\
\hline$T_{5}^{6, h m}$ & 1.32 & 1.89 & 1.95 & 5.16 \\
$T_{5}^{6, l m}$ & 2.05 & 3.30 & 3.35 & 8.70 \\
\hline
\end{tabular}

A second possibility to test for the presence of a fairness effect is to compare directly $T_{5}^{6, l m}$ with $T_{5}^{6, h m}$.

Result 6. Consistently with Conjecture 3 (fairness effect), the effectiveness of the CM is significantly higher in $T_{5}^{6, l m}$ than in $T_{5}^{6, h m}$.

Support for result 6. Table 14 shows the results of the Mann-Witney test comparing $T_{5}^{6, h m}$ and $T_{5}^{6, l m}$ for the various sequences and the overall periods. While $T_{5}^{6, l m}$ is more effective over the whole number of periods, it is however not always significantly larger at the 5\% significance threshold.

Table 14: Comparisons of the number of times groups reach a PO between treatments (MannWhitney)

\begin{tabular}{ccccc}
\hline \hline \multirow{3}{*}{ Comparisons } & Periods & Periods & Periods & All \\
& 2 to 6 & 7 to 11 & 12 to 16 & periods \\
& p-value & p-value & p-value & p-value \\
\hline$T_{5}^{6, h m}-T_{5}^{6, l m}$ & 0.0997 & 0.0288 & 0.0755 & 0.0296 \\
& $*$ & $* *$ & $*$ & $* *$ \\
\hline
\end{tabular}

\subsection{Relative importance of barriers to success}

This section runs a panel data logistic regression in order to complement the previous test results, with the aim to quantify and to appraise the relative importance of the hurdles to the effectiveness 
of the CM across treatments. Variables used in the regression are presented in Table 15. Results are shown in Table 16.

Table 15: Definitions of the variables included in the Logit regression

\begin{tabular}{ll}
\hline \hline PONE & $=1$ if the group reaches an optimal equilibrium, 0 otherwise (dependent variable) \\
\hline Nb_options & $=$ Number of available options in stage 1 \\
\hline Nb_NEq_theo & $=$ Number of predicted Nash equilibria \\
\hline ineq_OPNE=0 & $=1$ if the group belongs to Treatment $T_{5}^{6, l m}$, where a PONE has equal payoffs \\
\hline ineq_OPNE=16 & $=1$ if the group belongs to Treatment $T_{5}^{6, h m}$, where a PONE has a payoffs \\
\hline inv_period & $=1 /$ period \\
A_per1 & $=1$ if players 1 chooses option A in the first part of the game, \\
& 0 otherwise \\
PONE_t-1 & $=1$ if the group reached an optimal equilibrium at period $t-1$, \\
& 0 otherwise
\end{tabular}

Only one variable, the fact of choosing option A in the first period (A_per1), is not significant (even at the $10 \%$ level). The CM seems to affect equally subjects who are prone to cooperation and those who exhibit the usual self-interest rationality.

The second less significant variable is the number of Nash equilibria (it is significant only at the $10 \%$ level). This is countertintuitive at first sight, but consistent with Result 5 of Section 4.2 and the discussion therein.

All the other variables are significant at the $5 \%$ level, or even at the $1 \%$ level. And they play the role one may expect. Increasing the number of options, ceteris paribus, decreases the performance of the mechanism. Time has a vanishing effect, which can be interpreted as the role of learning. Subjects refine their knowledge over periods, and once a PONE has been achieved it is very likely that it will continue to occur in subsequent periods (that is, PONE_t-1 is significant). The role of inequality goes through the dummies ineq_OPNE=0 and ineq_OPNE $=16$. The first dummy indicates the presence of a PONE with equal payoffs, hence no inequality. Combined with the presumption of inequality aversion from the subjects, the presence of such an outcome sharpens the predictive power of the CM. In addition, and maybe independently of the absence of inequality, one may remember that a symmetric outcome is a focal point (Schelling, 1960). The second dummy, ineq_OPNE=16, indicates the presence of a PONE with the highest payoff 
Table 16: Probability that groups choose a PONE: random effects Logit regression

\begin{tabular}{cccc}
\hline \hline Ind. variables & coefficients & P-value & Marg. effect dy/dx \\
\hline Nb_options & $-1.853375^{* * *}$ & 0.002 & -0.4594704 \\
Nb_NEq_theo & $0.6770701^{*}$ & 0.081 & 0.1678525 \\
ineq_OPNE=0 & $1.430531^{* *}$ & 0.011 & 0.3127493 \\
ineq_OPNE=16 & $2.501657^{* *}$ & 0.040 & 0.4631627 \\
inv_period & $-2.109101^{* * *}$ & 0.001 & -0.5228673 \\
A_per1 & 0.1645862 & 0.690 & 0.0405842 \\
PONE_t-1 & $1.244413^{* * *}$ & 0.000 & 0.298361 \\
Constant & $3.866961^{* * *}$ & 0.000 & - \\
\hline log_likelihood & -819.48106 & & \\
\hline sigma_u & 1.596626 & & \\
rho & 0.4365779 & & \\
LR test of rho & chi2 $2=141.96$ & Prob $=0.000$ & \\
*** Significant at the 0.01 level; $* *$ significant at the 0.05 & \\
level; * significant at the 0.1 level.
\end{tabular}

inequality (12). This kind of PONE presumably increases subjects' ability to coordinate, not on this very unequal outome, but by contrast on another PONE that comparatively appears much less unfair. In other words, a very unfair equilibrium would help agents to coordinate on another equilibrium under the guise of a decent compromise.

The last column of Table 16 reports marginal effects. They are evaluated at the mean values of the independent variables. Among the three hurdles to effectiveness, choice overload and inequality prevail over mere coordination. The addition of a new option decreases the probability that agents choose a Pareto optimal outcome by 0.46 . The occurrence of a PONE with equal payoffs (respectively with a payoff gap of 16) increases this probability by 0.31 (respectively 0.46 ).

\section{Conclusion}

This paper shows that the effectiveness of the compensation mechanism depends on the size of the strategy space, more precisely on the number of options among which players can choose in the first stage. Increasing the number of options reduces the success of the mechanism, both for reaching optimal outcomes and for increasing social welfare. In theory, the explanation could be that increasing the number of options also increases the number of subgame perfect Nash equilibria 
and therefore alters group ability to coordinate. Nonetheless, we found that this effect owes much more to the number of options alone and the presumed bounded rationality of subjects.

Experimental results also showed that the distribution of equilibrium payoffs matters. However, the role of inequality is subtle. Allowing subjects to choose an option that provides equal payoffs to both players clearly increases the mechanism effectiveness, presumably because of agents' aversion to inequality, that drives the coordination process towards this very particular outcome ${ }^{10}$. For a related reason, but somehow surprisingly, adding a more unequal equilibrium does not necessarily impinge on the effectiveness of the CM. Such an addition increases the appeal of the other equilibria, i.e. their unfairness has not changed in the absolute but it is now reduced in relative terms.

The compensation mechanism can therefore create a fairness challenge in conflict resolution if i) optimal equilibria provides unequal payoffs and ii) none of them is considered a good compromise. This fairness conflict then prevents the resolution of the original conflict between collective and individual rationality. With the compensation mechanism, a trade-off between efficiency and equity may arise. But if the social planner can make equitable options available to agents, it also increases effectiveness.

\section{References}

[1] J. Andreoni and H. Varian. Preplay contracting in the prisoners' dilemma. Proceedings of the National Academy of Science, 96:10933-10938, 1999.

[2] J. Bracht, C. Figuières, and M. Ratto. Relative performance of two simple incentive mechanisms in a public goods experiment. Journal of Public Economics, 92:54-90, 2008.

[3] G. Charness, G.R. Frechette, and C-Z Qin. Endogenous transfers in the prisonerś dilemma game: An experimental test of cooperation and coordination. Games and Economic Behavior, 60:287-306, 2007.

\footnotetext{
${ }^{10}$ This result confirms that of Charness et al. (2007). In their paper they concluded that cooperation is substantially more likely with payment pairs that bring the mutual-cooperation payoffs closer together.
} 
[4] Y. Chen and R. Gazzale. When does learning in games generate convergence to nash equilibria? the role of supermodularity in an experimental setting. The American Economic Review, 94(5):1505-1535, 2004.

505

[5] D.J. Cooper and J.B. Van Huyck. Evidence on the equivalence of the strategic and extensive form representation of games. Journal of Economic Theory, 110:290-308, 2003.

[6] R.W. Cooper. Coordination Games. Cambridge University Press, Cambridge, 1998.

[7] L. Danziger and A. Schnytzer. Implementing the lindahl voluntary-exchange mechanism. European Journal of Political Economiy, 7(1):55-64, 1991.

[8] U. Fischbacher. z-tree: Zurich toolbox for ready-made economic experiments. Experimental Economics, 10(2):171-178, 2007.

[9] J.M. Guttman. Understanding collective actions: matching behavior. The American Economic Review, Papers and Proceedings, 68(2):251-255, 1978.

[10] J.M. Guttman. A non-cournot model of voluntary collective action. Economica, 54(213):1$19,1987$.

[11] Y. Hamaguchi, S. Mitani, and T. Saijo. Does the varian mechanism work? - emissions trading as an example. International Journal of Business and Economics, 2(2):85-96, 2003.

[12] S.S. Iyengar and E. Kamenica. Choice proliferation, simplicity seeking, and asset allocation. Journal of Public Economics, 94(7-8):530-539, 2010.

[13] B. Kõszegi and M. Rabin. A model of reference-dependent preferences. The Quaterly Journal of Economics, 121(4):1133-1165, 2006.

[14] B. Kõszegi and M. Rabin. Reference-dependent risk attitudes. The American Economic Review, 97(4):1047-1073, 2007.

[15] D. Kahneman. Maps of bounded rationality : Psychology for behavioral economics. American Economic Review, 93(5):1449-1475, 2003. 
[16] M. Rabin. Incorporating fairness into game theory and economics. The American Economic Review, 83(5):1281-1302, 1993.

[17] T. Schelling. The Strategy of Conflict. Harvard University Press, 1960.

[18] H. Simon. A behavioral model of rational choice. Quaterly Journal of Economics, 69:99-118, 1955.

[19] H. Varian. A solution to the problem of externalities when agents are well-informed. The American Economic Review, 84(5):1278-1293, 1994. 


\section{Appendix 1: Example of instructions (Treatment $T_{3}^{3, m}$ )}

We thank you for agreeing to participate in this experiment on decision making. It will be rewarded and your earnings will depend on your decisions and on decisions taken by other players. Your decisions will be collected through a computer network and processed anonymously. You will specify your choices to the computer in front of you and it will tell you your earnings (in Euros) throughout the experiment. From now until the end of the experiment, we ask you not to communicate with each other. If you have any questions, raise your hand and a monitor will answer you in private.

\section{Roles}

There are two roles in the experiment: role 1 and role 2. We call Player 1 a player who has the role 1 and Player 2 a player who has the role 2. There are as many Players 1 as Players 2 in the room. You can be a Player 1 or a Player 2. At the beginning of the experiment, the central computer will randomly form pairs with one Player 1 and one Player 2. So, each player one will interact with a Player 2. Pairs remain the same during all the experiment. So you will always interact with the same person. You cannot know who he/she is and he cannot know you you are.

\section{General Progress}

The experiment is divided in two parts. The first one lasts one period and the second one lasts 15 periods. 


\section{Final Earnings}

The final payment you will receive for this experiment is caculted as follows: at the end of the

560 part) will be randomly drawn for each pair. Your final payment will be the one you earned at this period.

Once all participants have finished reading the instructions, a monitor will read them out. Then, 565 you will have to fill a survey to see if you understood everything well. Once all participants have finished filling the survey, the experiment will begin. Instructions fo the second part will be given to you after the end of the first part.

\section{Part 1}

570

\section{Progress}

There is only one period in Part 1. The progress of Part 1 is summarized in figure 1 below.

Only the Player 1 has to take a decision: he has to choose between option A and option B.

At the end of Part 1, each player will be informed of:

- Players 1's decision,

- his earnings,

- the other player's earnings. 


\section{Payoffs}

Payoffs are shown in the figure 1 below. Player 1's payoff $\left(\pi_{1}\right)$ corresponds to the numbers given in the first row. Player 2's payoff $\left(\pi_{2}\right)$ corresponds to the numbers given in the second row.

Figure 3: Possible choices and payoffs for Player 1 and 2 in the Part 1

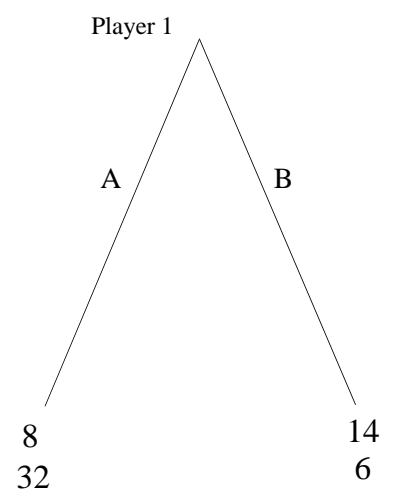

${ }_{585} \quad$ Figure 1's explanation

- If Player 1 choose option A, Player 1 earns 8 euros and Player 2 earns 32 euros.

- If Player 1 choose option B, Player 1 earns 14 euros and Player 2 earns 6 euros. 


\section{Part 2}

There are 15 periods in the Part 2 and there are two stages in each period. The progress of each period of Part 2 is summarized in figure 1 (next page).

- During the first stage, both players have to take a decision:

- Player 1 has to choose between three options : 1, 2 ou 3.

- Player 2 has to choose between three options : 1, 2 ou 3.

At the end of this first stage players will be informed of the other one's decision.

- During the second stage, only Player 1 has to take a decision: he has to choose between option A and option B (knowing the choices that have been made in the first stage).

At the end of each period, each player will be informed of :

- all decisions taken,

- his earnings,

- the other player's earnings.

Payoffs are shown in the figure 2 below (next page). Player 1's payoff $\left(\pi_{1}\right)$ corresponds to the numbers given in the first row. Player 2's payoff $\left(\pi_{2}\right)$ corresponds to the numbers given in the second row. 
Figure 4: Possible choices and payoffs for Player 1 and 2 in the Part 2.

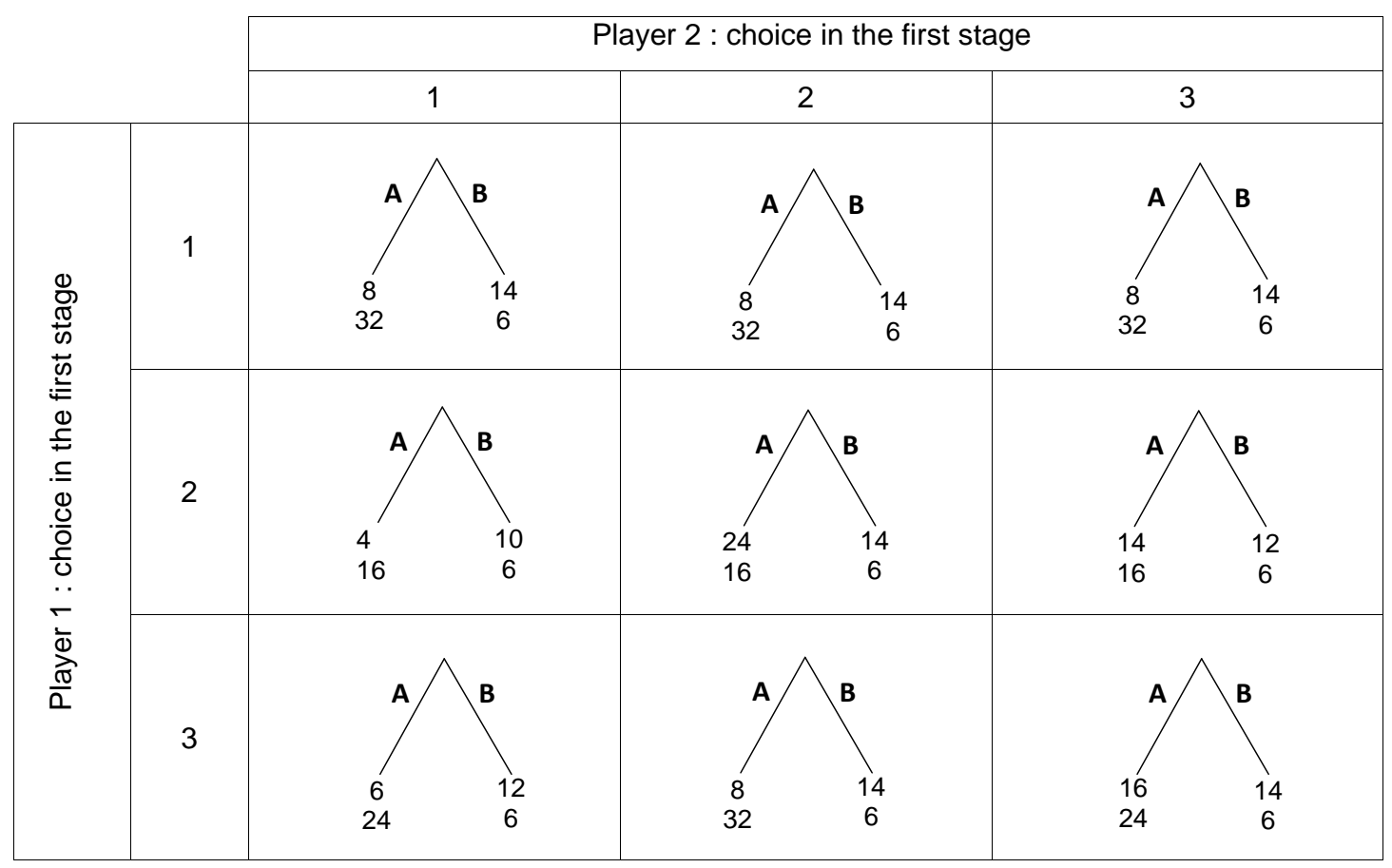

- If Player 1 chooses option 2 during the first stage,

- if Player 2 chooses option 1 during the fist stage,

* if Player 1 chooses option A in the second stage, Player 1 earns 4 euros and Player 2 earns 16 euros.

* if Player 1 chooses option B in the second stage, Player 1 earns 10 euros and Player 2 earns 6 euros. 


\section{Appendix 2: Games played in each treatment}

Table 17: Payoffs in Treatment $T_{2}^{2, m}$, Part 2

\begin{tabular}{|c|c||c|c||c|c|}
\cline { 3 - 6 } \multicolumn{2}{c|}{} & \multicolumn{2}{c||}{ Option 0 } & \multicolumn{2}{c|}{ Option 1 } \\
\cline { 2 - 6 } \multicolumn{2}{c|}{} & $\Pi_{1}$ & $\Pi_{2}$ & $\Pi_{1}$ & $\Pi_{2}$ \\
\hline \hline \multirow{2}{*}{ Option 0 } & $\mathrm{A}$ & 8 & 32 & 8 & 32 \\
\cline { 2 - 6 } & $\mathrm{B}$ & $\mathbf{1 4}$ & $\mathbf{6}$ & 14 & 6 \\
\hline \hline Option 1 & $\mathrm{A}$ & 4 & 16 & $\mathbf{2 4}$ & $\mathbf{1 6}$ \\
\cline { 2 - 6 } & $\mathrm{B}$ & 10 & 6 & 14 & 6 \\
\hline
\end{tabular}

Table 18: Payoffs in Treatment $T_{3}^{2, m}$, Part 2

\begin{tabular}{|c|c||c|c||c|c||c|c|}
\cline { 3 - 8 } \multicolumn{2}{c|}{} & \multicolumn{2}{c||}{ Option 1 } & \multicolumn{2}{c|}{ Option 2 } & \multicolumn{2}{c|}{ Option 3 } \\
\cline { 3 - 8 } \multicolumn{2}{c|}{} & $\Pi_{1}$ & $\Pi_{2}$ & $\Pi_{1}$ & $\Pi_{2}$ & $\Pi_{1}$ & $\Pi_{2}$ \\
\hline \hline \multirow{2}{*}{ Option 1 } & $\mathrm{A}$ & 8 & 32 & 8 & 32 & 8 & 32 \\
\cline { 2 - 8 } & $\mathrm{B}$ & $\mathbf{1 4}$ & $\mathbf{6}$ & 14 & 6 & 14 & 5 \\
\hline \hline \multirow{2}{*}{ Option 2 } & $\mathrm{A}$ & 4 & 16 & $\mathbf{2 4}$ & $\mathbf{1 6}$ & 14 & 15 \\
\cline { 2 - 8 } & $\mathrm{B}$ & 10 & 6 & 14 & 6 & 12 & 6 \\
\hline \hline \multirow{2}{*}{ Option 3 } & $\mathrm{A}$ & 6 & 24 & 8 & 32 & 13 & 24 \\
\cline { 2 - 8 } & $\mathrm{B}$ & 12 & 6 & 14 & 6 & 14 & 5 \\
\hline
\end{tabular}


Table 19: Payoffs in Treatment $T_{3}^{3, m}$, Part 2

\begin{tabular}{|c|c||c|c||c|c||c|c|}
\cline { 3 - 8 } \multicolumn{2}{c|}{} & \multicolumn{2}{c||}{ Option 1 } & \multicolumn{2}{c||}{ Option 2 } & \multicolumn{2}{c|}{ Option 3 } \\
\cline { 3 - 8 } \multicolumn{2}{c|}{} & $\Pi_{1}$ & $\Pi_{2}$ & $\Pi_{1}$ & $\Pi_{2}$ & $\Pi_{1}$ & $\Pi_{2}$ \\
\hline \hline \multirow{2}{*}{ Option 1 } & $\mathrm{A}$ & 8 & 32 & 8 & 32 & 8 & 32 \\
\cline { 2 - 8 } & $\mathrm{B}$ & $\mathbf{1 4}$ & $\mathbf{6}$ & 14 & 6 & 14 & 6 \\
\hline \hline \multirow{2}{*}{ Option 2 } & $\mathrm{A}$ & 4 & 16 & $\mathbf{2 4}$ & $\mathbf{1 6}$ & 14 & 16 \\
\cline { 2 - 8 } & $\mathrm{B}$ & 10 & 6 & 14 & 6 & 12 & 6 \\
\hline \hline Option 3 & $\mathrm{A}$ & 6 & 24 & 8 & 32 & $\mathbf{1 6}$ & $\mathbf{2 4}$ \\
\cline { 2 - 8 } & $\mathrm{B}$ & 12 & 6 & 14 & 6 & 14 & 6 \\
\hline
\end{tabular}

Table 20: Payoffs in Treatment $T_{5}^{3, m}$, Part 2

\begin{tabular}{|c|c|c|c|c|c|c|c|c|c|c|c|}
\hline & \multicolumn{2}{|c|}{ Option 1} & \multicolumn{2}{|c|}{ Option 2} & \multicolumn{2}{|c|}{ Option 3} & \multicolumn{2}{|c|}{ Option 4} & \multicolumn{2}{|c|}{ Option 5} \\
\hline & & $\Pi_{1}$ & $\overline{\Pi_{2}}$ & $\Pi_{1}$ & $\Pi_{2}$ & $\Pi_{1}$ & $\Pi_{2}$ & $\Pi_{1}$ & $\Pi_{2}$ & $\Pi_{1}$ & $\Pi_{2}$ \\
\hline \multirow[t]{2}{*}{ Option 0} & A & 8 & 32 & 8 & 32 & 8 & 32 & 8 & 32 & 8 & 32 \\
\hline & $\mathrm{B}$ & 14 & 6 & 14 & 5 & 14 & 6 & 14 & 6 & 14 & 6 \\
\hline \multirow[t]{2}{*}{ Option 1} & $\overline{\mathrm{A}}$ & 7 & 28 & 12 & 28 & 8 & 32 & 8 & 32 & $\overline{88}$ & 32 \\
\hline & $\mathrm{B}$ & 13 & 6 & 14 & 5 & 14 & 6 & 14 & 6 & 14 & 6 \\
\hline \multirow[t]{2}{*}{$\overline{\text { Option } 2}$} & $\bar{A}$ & $\overline{6}$ & 24 & 11 & 24 & 16 & 24 & 8 & 32 & 8 & 32 \\
\hline & $\mathrm{B}$ & 12 & 6 & 13 & 6 & 14 & 6 & 14 & 6 & 14 & 6 \\
\hline \multirow[t]{2}{*}{ Option 3} & $\mathrm{~A}$ & 4 & 16 & 9 & 16 & 14 & 16 & 24 & 16 & 8 & 32 \\
\hline & $\mathrm{B}$ & 10 & 6 & 11 & 6 & 12 & 6 & 14 & 6 & 14 & 6 \\
\hline \multirow[t]{2}{*}{$\overline{\bar{O} \text { Option } 4}$} & A & 3 & 12 & 8 & 12 & 13 & 12 & 23 & 12 & 29 & 11 \\
\hline & $\mathrm{B}$ & 9 & 6 & 10 & 6 & 11 & 6 & 13 & 6 & 14 & 6 \\
\hline
\end{tabular}


Table 21: Payoffs in Treatment $T_{5}^{6, h m}$, Part 2

\begin{tabular}{|c|c|c|c|c|c|c|c|c|c|c|c|}
\hline & \multicolumn{2}{|c|}{ Option 1} & \multicolumn{2}{|c|}{ Option 2} & \multicolumn{2}{|c|}{ Option 3} & \multicolumn{2}{|c|}{ Option 4} & \multicolumn{2}{|c|}{ Option 5} \\
\hline & & $\Pi_{1}$ & $\Pi_{2}$ & $\Pi_{1}$ & $\Pi_{2}$ & $\Pi_{1}$ & $\Pi_{2}$ & $\Pi_{1}$ & $\Pi_{2}$ & $\Pi_{1}$ & $\Pi_{2}$ \\
\hline \multirow[t]{2}{*}{ Option 0} & $\bar{A}$ & 8 & 32 & 8 & 32 & 8 & 32 & 8 & 32 & $\overline{8}$ & 32 \\
\hline & B & 14 & 6 & 14 & 6 & 14 & 6 & 14 & 6 & 14 & 6 \\
\hline \multirow[t]{2}{*}{ Option 1} & $\bar{A}$ & 7 & 28 & 12 & 28 & $\overline{88}$ & 32 & 8 & 32 & $\overline{88}$ & 32 \\
\hline & $\mathrm{B}$ & 13 & 6 & 14 & 6 & 14 & 6 & 14 & 6 & 14 & 6 \\
\hline \multirow[t]{2}{*}{ Option 2} & $\mathrm{~A}$ & 6 & 24 & 11 & 24 & 16 & 24 & 8 & 32 & 8 & 32 \\
\hline & B & 12 & 6 & 13 & 6 & 14 & 6 & 14 & 6 & 14 & 6 \\
\hline \multirow[t]{2}{*}{ Option 3} & $\mathrm{~A}$ & 4 & 16 & 9 & 16 & 14 & 16 & 24 & 16 & 8 & 32 \\
\hline & $\mathrm{B}$ & 10 & 6 & 11 & 6 & 12 & 6 & 14 & 6 & 14 & 6 \\
\hline \multirow[t]{2}{*}{ Option 4} & A & 3 & 12 & $\overline{8}$ & 12 & $\overline{13}$ & 12 & 23 & $\overline{12}$ & 28 & $\overline{12}$ \\
\hline & $\mathrm{B}$ & 9 & 6 & 10 & 6 & 11 & 6 & 13 & 6 & 14 & 6 \\
\hline
\end{tabular}

Table 22: Payoffs in Treatment $T_{5}^{6, l m}$, Part 2

\begin{tabular}{|c|c|c|c|c|c|c|c|c|c|c|c|}
\hline & \multicolumn{2}{|c|}{ Option 1} & \multicolumn{2}{|c|}{ Option 2} & \multicolumn{2}{|c|}{ Option 3} & \multicolumn{2}{|c|}{ Option 4} & \multicolumn{2}{|c|}{ Option 5} \\
\hline & & $\Pi_{1}$ & $\Pi_{2}$ & $\Pi_{1}$ & $\Pi_{2}$ & $\Pi_{1}$ & $\Pi_{2}$ & $\Pi_{1}$ & $\Pi_{2}$ & $\Pi_{1}$ & $\Pi_{2}$ \\
\hline \multirow[t]{2}{*}{ Option 0} & $\overline{\mathrm{A}}$ & $\overline{88}$ & 32 & $\overline{8} 8$ & 32 & $\overline{88}$ & 32 & 8 & 32 & $\overline{8} 8$ & 32 \\
\hline & B & 14 & 6 & 14 & 6 & 14 & 6 & 14 & 6 & 14 & 6 \\
\hline \multirow[t]{2}{*}{ Option 1} & $\overline{\mathrm{A}}$ & $\overline{7}$ & $\overline{28}$ & 12 & 28 & $\overline{88}$ & 32 & $\overline{88}$ & 32 & 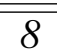 & 32 \\
\hline & B & 13 & 6 & 14 & 6 & 14 & 6 & 14 & 6 & 14 & 6 \\
\hline \multirow[t]{2}{*}{ Option 2} & $\overline{\mathrm{A}}$ & $\overline{\overline{6}}$ & $\overline{24}$ & $\overline{111}$ & 24 & 16 & 24 & 8 & 32 & $\overline{88}$ & 32 \\
\hline & B & 12 & 6 & 13 & 6 & 14 & 6 & 14 & 6 & 14 & 6 \\
\hline \multirow[t]{2}{*}{ Option 3} & $\overline{\bar{A}}$ & $\overline{5}$ & $\overline{20}$ & 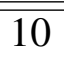 & 20 & $\overline{c 15}$ & 20 & 20 & 20 & $\overline{78}$ & 32 \\
\hline & B & 11 & 6 & 12 & 6 & 13 & 6 & 14 & 6 & 14 & 6 \\
\hline \multirow[t]{2}{*}{ Option 4} & $\bar{A}$ & $\overline{4}$ & 16 & $\overline{99}$ & 16 & 14 & 16 & $\overline{19}$ & 16 & 24 & 16 \\
\hline & B & 10 & 6 & 11 & 6 & 12 & 6 & 13 & 6 & 14 & 6 \\
\hline
\end{tabular}




\section{Documents de Recherche parus en 2013}

DR n²013-01: Estelle MIDLER, Charles FIGUIÈRES, Marc WILLINGER «Choice overload, coordination and inequality: threehurdles to the effectiveness of the compensationmechanism?» 
Contact :

Stéphane MUSSARD : mussard@lameta.univ-montp1.fr 


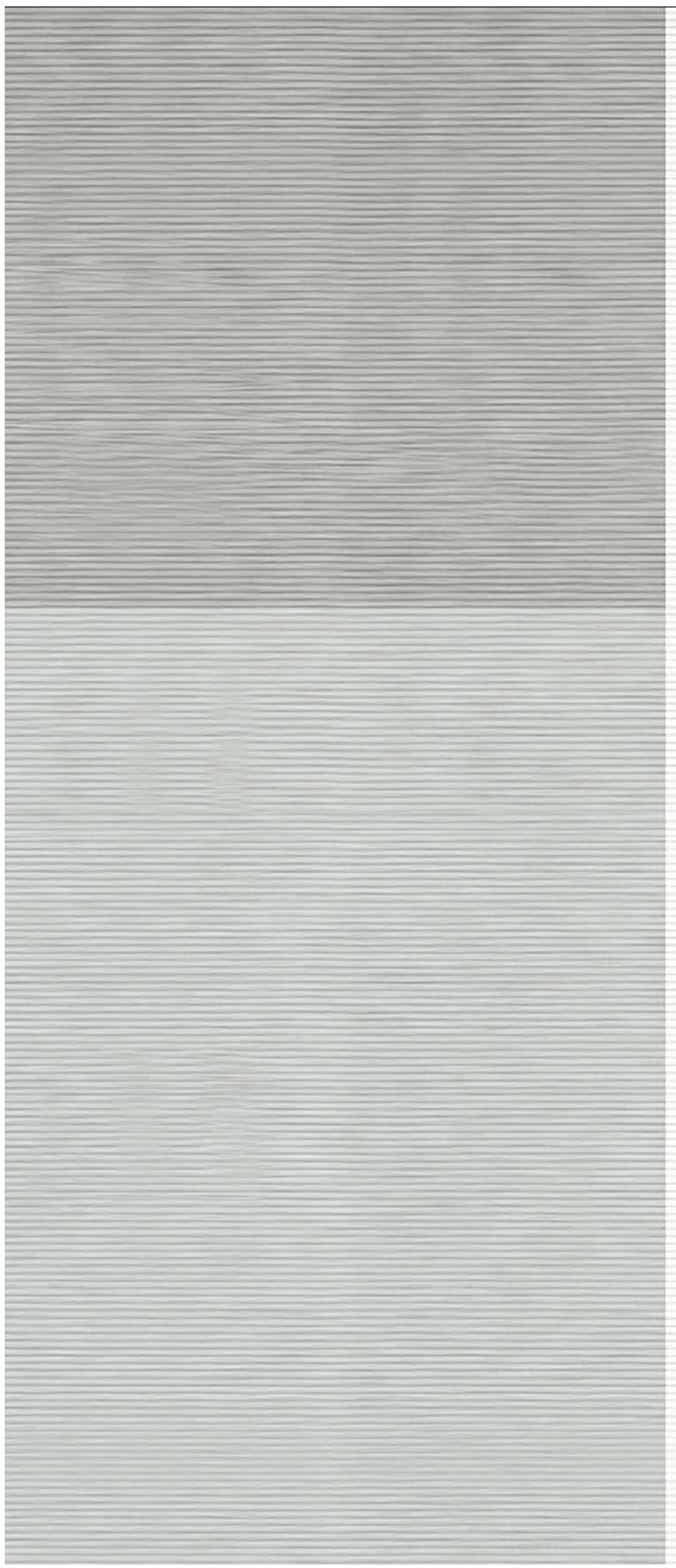

